\title{
Comportamento das exportações da agroindústria brasileira do café e interações com
} agentes produtivos

\author{
Export behavior of the Brazilian coffee agribusiness and interactions with production elements \\ Comportamiento de las exportaciones de la agroindústria brasileña del café e interaciones com los \\ agentes de producción
}

Recebido: 03/03/2021 | Revisado: 10/03/2021 | Aceito: 12/03/2021 | Publicado: 20/03/2021

Lidiany dos Santos Soares

\author{
ORCID: https://orcid.org/0000-0002-3004-6515 \\ Universidade José do Rosário Vellano, Brasil \\ E-mail: lidysts@gmail.com \\ Ana Maria Santana do Amaral \\ ORCID: https://orcid.org/0000-0001-5150-9462 \\ Universidade José do Rosário Vellano, Brasil \\ E-mail: msa.ana@gmail.com \\ Tiago Teruel Rezende \\ ORCID: https://orcid.org/0000-0001-8389-2582 \\ Universidade José do Rosário Vellano, Brasil \\ E-mail: tiago.rezende@unifenas.br \\ Fernando Ferrari Putti \\ ORCID: https://orcid.org/0000-0002-0555-9271 \\ Universidade Estadual Paulista, Brasil \\ E-mail: fernando.putti@unesp.br \\ Bruno César Góes \\ ORCID: https://orcid.org/0000-0002-4409-1720 \\ Universidade José do Rosário Vellano, Brasil \\ E-mail: bruno.goes@unifenas.br
}

\begin{abstract}
Resumo
O café possui relativa importância para a balança comercial e para estrutura produtiva do agronegócio brasileiro, embora apresente dificuldades na agregação de valor às exportações. Com o objetivo de analisar o comportamento das exportações agroindustriais do café brasileiro e sua relação com agentes produtivos, este estudo considerou dados dos anos de 2001 a 2019, que estão relacionados a produção, área e pés produtivos. Foram também avaliados dados sobre o volume e valor de café exportados. Todas as variáveis foram submetidas à análise estatística de correlação. $\mathrm{O}$ volume de produção, a produtividade (sacas por hectare), área e pés plantados relacionaram-se inversamente às variações cambiais, com respostas positivas da quantidade de pés produtivos aos aumentos de preço. As exportações cafeeiras demonstraram maior concentração na primeira fase da cadeia agroindustrial com pequena evolução do café solúvel e sucessivos comportamentos de queda do café torrado e moído, que participa de $0,1 \%$ de toda exportação cafeeira realizada pelo país. Ainda que a agroindústria tenha apresentado aumentos médios de $4 \%$ e $3 \%$ ao ano no volume exportado de grãos e solúvel, a cadeia produtiva passa por estagnação nos valores comercializados no mercado externo, que correlacionaram de forma negativa com a taxa cambial. Estes resultados demonstram que a forte concentração na fase inicial da cadeia produtiva de café brasileira é sensível às variações da taxa de câmbio, enquanto os cafés solúvel, torrado e moído possuem dificuldades para expansão no mercado internacional, culminando no desafio da criação de políticas de valorização destes produtos.
\end{abstract}

Palavras-chave: Câmbio; Grão; Solúvel; Torrado.

\begin{abstract}
Coffee has relative importance for the trade balance and for the productive structure of Brazilian agribusiness, although it presents difficulties in adding value to exports. In order to analyze the behavior of Brazilian coffee industrial-agricultural exports and its relationship with production agents, this study considered data from the years 2001 to 2019, which are related to production, area and production feet. Data on the quantity and value of exported coffee were also evaluated. All variables were subjected to statistical correlation analysis. Production quantity, productivity (bags per hectare), area and planted trees were inversely related to exchange rate variations, with positive responses of the quantity of productive trees to price increases. Coffee exports were more concentrated in the first stage of the industrial-agricultural chain, with a small increase in soluble coffee and successive decreases in roasted and ground coffee, which accounts for $0.1 \%$ of all coffee exports in the country. Even though the industrial-
\end{abstract}


agricultural has shown average increases of $4 \%$ and $3 \%$ annual in the volume of exported beans and soluble coffee, the production chain is experiencing stagnation in the values sold in the foreign market, which correlate negative way with the exchange rate. These results show that the strong concentration in the initial stage of the Brazilian coffee production chain is sensitive to exchange rate variations, while soluble, roasted and ground coffees have difficulties in expanding in the international market, culminating in the challenge of creating valuation policies for these products.

Keywords: Exchange; Grain; Soluble; Roasted.

\section{Resumen}

El café tiene relativa importancia para la balanza comercial y para la estructura productiva del agronegocio brasileño, aunque presenta dificultades en la agregación de valor a las exportaciones. Con el objetivo de analizar el comportamiento de las exportaciones agroindustriales del café brasileño y su relación con agentes productivos, este estudio consideró datos de los años 2001 a 2019, que están relacionados a la producción, área y pies productivos. También se evaluaron datos sobre el volumen y el valor del café exportado. Todas las variables fueron sometidas al análisis estadístico de correlación. El volumen de producción, la productividad (sacos per hectárea), área y pies plantados se relacionaron inversamente a las variaciones de cambio, con respuestas positivas de la cantidad de pies productivos, a los aumentos de precio. Las exportaciones cafeteras demostraron mayor concentración en la primera fase de la cadena agroindustrial con pequeña evolución del café soluble y sucesivos comportamientos de caída del café tostado y molido, que participa del $0,1 \%$ de toda exportación cafetera realizada por el país. Aunque la agroindustria ha presentado aumentos medios del $4 \%$ y $3 \%$ al año en el volumen exportado de granos y soluble, la cadena productiva pasa por estancamiento en los valores comercializados en el mercado externo, que correlacionaron de forma negativa con el tipo de cambio. Estos resultados demuestran que la fuerte concentración en la fase inicial de la cadena productiva de café brasileña es sensible a las variaciones del tipo de cambio, mientras que los cafés solubles, tostados y molidos tienen dificultades para la expansión en el mercado internacional, culminando en el desafío de la creación de políticas de valorización de estos productos.

Palablas clave: Cambio; Grano; Soluble; Tostado.

\section{Introdução}

O Brasil é líder no ranking de produção e exportação mundial de café e sua relação com a agroindústria, considerada economicamente positiva visto seus significativos reflexos no produto interno bruto do país (Companhia Nacional de Abastecimento, 2020 e Marques, 2020). Com representatividade de um terço do volume exportado no mundo, a Organização Internacional do Café (2020), destaca que a produção cafeeira possui estreito vínculo com o desenvolvimento econômico do país, pois influenciou fortemente a estruturação das regiões mais prósperas, consolidando o produto como uma bebida consumida por todas as classes sociais (Lacerda, 2018; Faleiros \& Tosi, 2019).

A comercialização do café é realizada geralmente de forma não industrializada ou industrializada, o que significa dizer que o primeiro método tem como produto final o café verde enquanto o segundo, contempla os cafés solúveis e torrados. O subsetor de cafés solúveis apresenta alta concentração industrial, com $98 \%$ da produção nacional sob responsabilidade de apenas 11 empresas, enquanto no segmento de café torrado e moído, existem cerca de 1200 torrefadoras, sendo a maioria de pequeno porte (Ponciano et al., 2009).

De acordo com o Ministério da Agricultura, Pecuária e Abastecimento (2019), o café está entre os dez produtos mais representativos das exportações do agronegócio brasileiro. O ano de 2020 foi marcado por recorde nas exportações que aumentaram 9,4\% em relação ao ano anterior, o que representa um volume de 44,5 milhões de sacas de café verde, solúvel e torrado e moído (Conselho de Exportadores de Café do Brasil, 2020). Porém, ao longo do tempo o grão e seus derivados vêm apresentando queda nos preços internacionais (Sereia et al., 2008) que no mercado mundial, são afetados por ajustes motivados pelas mudanças de oferta e demanda nos países exportadores e importadores (Begg \& Dornbusch, 2005).

Condições climáticas, técnicas de manejo e a bienalidade da cultura são fatores que exercem influência direta no volume de produção cafeeira (Camargo, 2010; Dawid \& Hailu, 2018; Verdin Filho et al., 2016). Além destes, Matiello (2005) aponta o preço como maior influenciador na decisão dos cafeicultores de investir em ampliações ou reduções na cultura (Barreto \& Zugaib, 2016). 
Estudos realizados por Copetti e Coronel (2019), indicaram aumento nas exportações brasileiras do café verde no período 2000 a 2018, motivados principalmente pelo fortalecimento da parceria comercial do país com os Estados Unidos. Porém, com tantas potencialidades do Brasil, os cafés solúvel, torrado e moído enfrentam problemas de competitividade, pois diversos países importam o grão verde brasileiro, industrializam e exportam estes mesmos cafés. O que tem ocorrido ao longo do tempo, é um crescimento das exportações destes dois tipos de café pelo mundo e uma estagnação das exportações brasileiras, pois o país enfrenta dificuldades como as variações de preço, oferta total de café Robusta utilizado na composição de blends e pequena margem para repasse dos aumentos de preços advindos de custos da matéria-prima, resultando em redução na rentabilidade e do interesse nas exportações destes produtos (Sório, 2015). Além destas situações, a entrada do café torrado e moído no mercado internacional requer o cumprimento de vários pré-requisitos que limitam as exportações, enquanto o café solúvel enfrenta desigualdades tarifárias entre países concorrentes (Sereia, 2012).

Estudos sobre as exportações da agroindústria brasileira já foram realizados e em geral, tratam de temas relativos à competitividade do Brasil e sua participação no comércio exterior, frente a outros países produtores. Como exemplo, Sereia et al. (2008) avaliaram a dinâmica competitiva do complexo cafeeiro do Brasil e do estado do Paraná constatando que as variações nos preços internacionais e influências de políticas internacionais de proteção, exercem impactos decisivos à comercialização do café brasileiro no mercado externo. Innocentini (2015), identificou linhas de atuação política nos segmentos iniciais e finais da cadeia produtiva cafeeira com propostas para a consolidação do agronegócio no país. Trabalhos recentes como o de Copetti e Coronel (2019) e Takano et al. (2021), avaliaram a competitividade e participação do Brasil no mercado de exportações cafeeiras, mas também limitaram-se a compreensão da concorrência e ações políticas.

A relação entre as exportações brasileiras da agroindústria do café e os fatores produtivos ainda não foi analisada. Esta é uma importante compreensão que pode preencher lacunas sobre a dinâmica deste relacionamento, tendo em vista o decréscimo da participação da cultura como um todo no mercado internacional.

A análise detalhada sobre a evolução destas exportações, a valorização dos produtos advindos da agroindústria e a o comportamento da produção faz-se necessária, pois pode contribuir para o fomento de ações e para a criação de políticas setoriais que ampliem a competitividade da cafeicultura (Gurgel, 2014) e também para a busca de alternativas para potencializar a ascensão internacional do segmento.

Desta forma, este estudo tem como objetivo analisar o comportamento das exportações da agroindústria cafeeira e sua relação com fatores produtivos no mercado brasileiro.

\section{Metodologia}

\subsection{Fonte e abrangência dos dados}

Para análise das exportações brasileiras de café foram considerados tipos de café em grão, solúvel, torrado e moído, sendo os dados obtidos por meio de relatórios disponibilizados pelo Ministério do Desenvolvimento, Indústria e Comércio Exterior - MDIC e da Companhia Nacional de Abastecimento - CONAB. Foram considerados para a análise, o período compreendido entre os anos de 2001 a 2019 e examinadas as variáveis: produção (milhões de sacas), produtividade (sacas por hectare), área produtiva (milhões de hectares), quantidade de pés em produção ( em milhões de pés), quantidade de sacas exportadas (60 quilos), valor médio unitário da saca (U\$), exportações totais do país (bilhões de U\$) e taxa cambial (R\$).

\subsection{Análise estatística e softwares utilizados}

O estudo utilizou método quantitativo, envolvendo dados numéricos capazes de fornecer informações para aplicação de análises e estimativas (Pereira et al., 2018). 
Dados do café em grão, foram avaliados de acordo com o volume de sacas de 60 quilos. As variáveis relativas a quantidade de café solúvel, torrado e moído foram convertidas do peso líquido para saca de 60 quilos, com base na metodologia aplicada pela Organização Internacional do Café - OIC, sendo a seguinte:

- Conversão solúvel em sacas de 60 kg: (peso líquido*2,60)/60

- Conversão torrado e moído em sacas de 60 kg: (peso líquido*1,19)/60

Para equivalência dos valores em dólar (sacas de café e exportações), foi utilizado o U.S. Bureau of Labor Statistics, que considera o Consumer Price Index - CPI na estatística de preços agregados, sendo amplamente utilizado em deliberações de política monetária dos Estados Unidos (Bryan e Cecchettit, 1993).

O Índice de Preços ao Consumidor - Amplo (IPCA) foi utilizado como deflator da taxa cambial, tendo em vista que seus valores estão expressos em moeda brasileira, sendo utilizado pelo Conselho Monetário Nacional como referência nas variações na taxa de juros e metas inflacionárias do país (Carrara e Correa, 2012).

Os dados foram submetidos à análise estatística multivariada realizada por meio do software MINITAB ${ }^{\circledR}$, com nível de significância a 1\% e 5\% (Fávero, 2017) e para elaboração gráfica dos resultados, fez-se uso do software SIGMAPLOT ${ }^{\circledR}$.

\section{Resultados e Discussão}

No período compreendido entre os anos de 2001 a 2019, a área destinada à cafeicultura apresentou queda de 16,8\% (Figura 1). O mesmo não ocorreu com o volume de pés plantados, pois houve aumento de $23 \%$ na comparação entre o primeiro e o último ano avaliados.

Figura 1. Evolução da produção cafeeira, área produtiva e pés plantados.

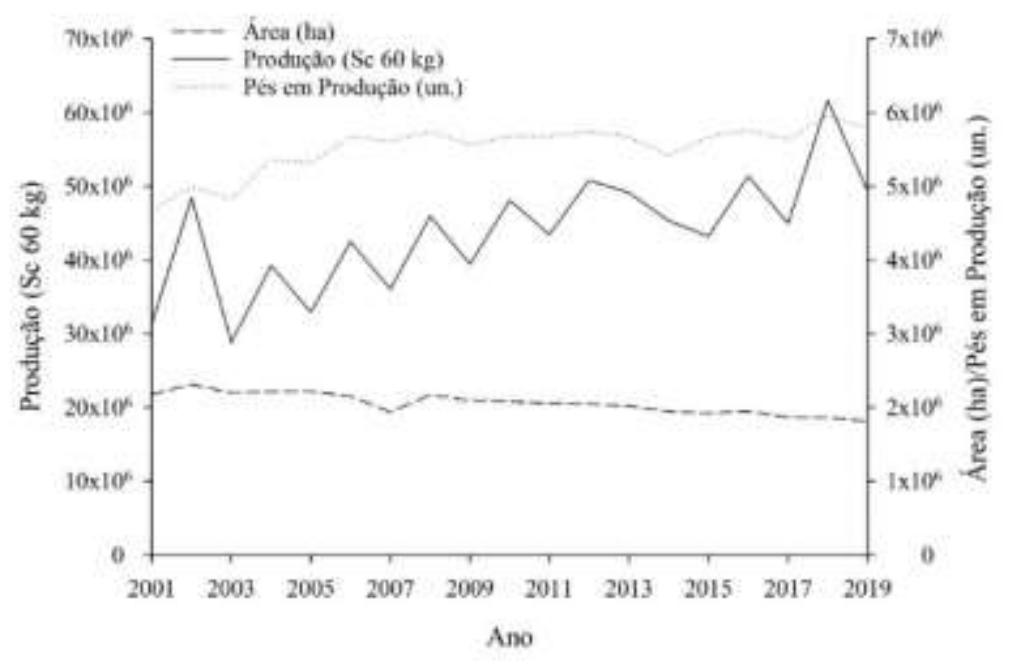

Fonte: Autores.

A produção, apesar das oscilações que em parte se justificam pela bienalidade da cultura, passou de 31.300 milhões de sacas em 2001, para 49.309 milhões de sacas em 2019. Estes comportamentos refletem melhor aproveitamento da área que pode ser feito por meio da redução do espaçamento no plantio e consequentemente, aumento no número de pés plantados. Além disto, vários fatores podem interferir no rendimento da cultura cafeeira, como por exemplo o sistema de plantio, adoção 
de programas de podas cíclicas, as condições do solo, variedade de café, idade das plantas, métodos de manejo e ainda a ocorrência de pragas e doenças (Verdin Filho et al., 2016, Victorino et al., 2016).

A quantidade de sacas de café em grão exportadas variou de forma positiva no período analisado, atingindo média de 4\% ao ano. Ressalta-se que em 2012, houve queda acentuada no volume de exportações, que provavelmente está relacionada às chuvas ocorridas em importantes regiões produtoras no início da colheita daquele ano. Este fato comprometeu a qualidade da produção e o encerramento da safra (Reuters, 2014). Nos anos seguintes, o volume exportado apresentou tendência de crescimento com taxa média de 6,4\% ao ano (Figura 2). Este comportamento demonstra o potencial produtivo cafeeiro, pois ainda que ocorram períodos de alta e baixa produtividade, ocasionados pela bienalidade da cultura, pragas e também por condições climáticas (Frederico, 2014), o país tem se consolidado como maior produtor e exportador mundial de café em grão (Conab, 2019).

Com variações inferiores ao grão, o café solúvel apresentou crescimento médio de 3\% ao ano durante o período de análise. Porém as exportações aumentaram de forma expressiva em 2019, quando foram comercializadas 3,82 milhões de sacas de café e variação de 15,8\% em relação ao ano anterior. De acordo com a Associação Brasileira da Indústria de Café Solúvel - ABIC (2020), este volume recorde foi motivado pelo aumento das importações de países como a Indonésia, Myanmar, México e Turquia. Para Ponciano (2009), a existência de forte concentração da produção do café solúvel no Brasil, o domínio de grandes multinacionais na Europa e América do Norte, além das reexportações feitas por países como a Alemanha e Itália, têm sido fortes barreiras entrentadas pelo solúvel brasileiro para expansão nos mercados externos.

No segmento de café torrado e moído, as exportações apresentaram consecutivas quedas. No ano de 2001 foram exportadas 69.964 sacas do produto, enquanto em 2019 este volume foi de 38.383 sacas, configurando uma redução de 45\% em relação ao primeiro ano de análise. Assim, o produto tem demonstrado baixo potencial de exportação, participando em apenas $0,1 \%$ de todo volume de cafés comercializados no mercado externo. A forte especialização de países desenvolvidos é um dos fatores apontados por Caldarelli, Gilio e Zilberman (2018) como obstáculo à concorrência do café torrado e moído no mercado exportador. Além disto, o Brasil apresenta elevado consumo doméstico e não possui regularidade de políticas públicas para o setor (Conceição et al., 2019).

Figura 2. Sacas exportadas de café em grão, solúvel, torrado e moído (2001 a 2019)

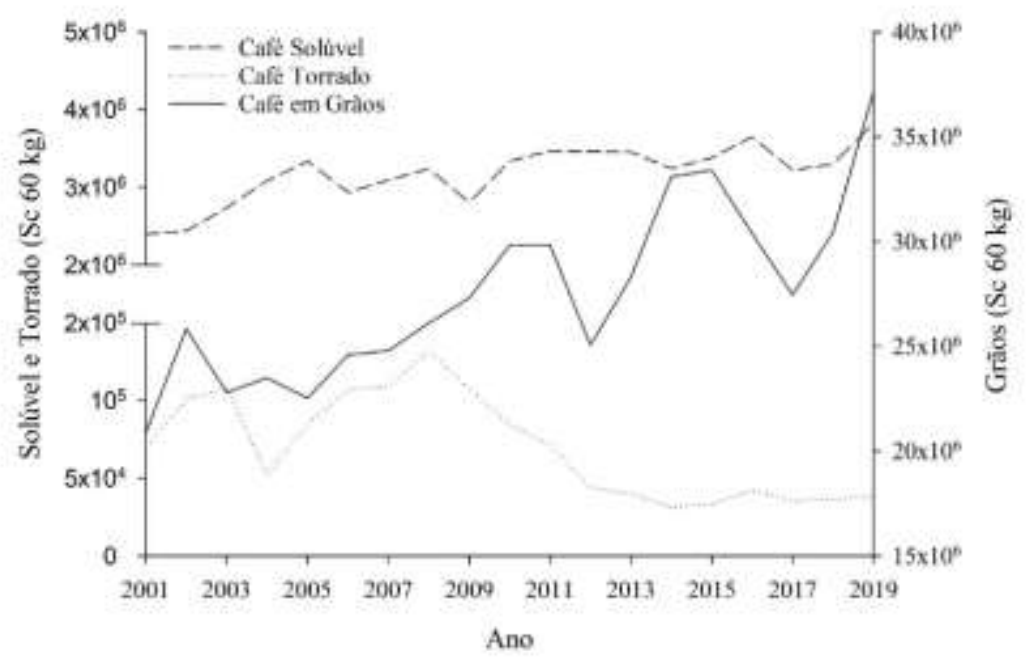

Fonte: Autores. 
Apesar de possuir papel relevante na pauta de exportações brasileiras, as receitas cambiais da cafeicultura apresentaram exíguo crescimento ao longo do período analisado. Em 2001, o grão representava 1,4\% do total das exportações do país, fechando o ano de 2019 com participação de 2\% nas receitas totais. Enquanto isso tanto o café solúvel quanto o torrado e moído apresentaram insignificantes avanços participativos nas exportações totais, passando de $0,22 \%$ para $0,24 \%$ e de $0,003 \%$ para $0,004 \%$, respectivamente.

Estes comportamentos indicam que, ainda que o café seja historicamente uma importante fonte de geração de divisas internacionais para a economia brasileira, suas contribuições às receitas cambiais, têm demonstrado certa estagnação ao longo do tempo. Este comportamento foi justificado por Ponciano et al. (2009), que concluiu que apesar das oscilações, o café tem passado por um processo de estabilização, como reação do mercado à política unilateral de sustentação de preços adotada pelo Brasil desde a década de 1960.

Nos anos de 2011 e 2012, verificou-se (Figura 3) significativos aumentos nos valores das exportações do café em grão. De acordo com o Centro de Estudos Avançados em Economia Aplicada - CEPEA (2013), estas variações positivas podem ser reflexo da baixa produção brasileira e mundial ocorrida naqueles anos e a manutenção da demanda global por café no mesmo período. Neste sentido, Moreira et al. (2019) constataram em seus estudos, que a volatilidade nos preços das commodities são respostas à oferta e demanda tanto nacionais como globais.

O café solúvel enfrenta fortes entraves a negociações de melhores preços, advindas de ações protecionistas da China e taxações existentes na União Europeia para entrada deste produto. Assim, indústrias de países concorrentes como Itália, Alemanha e Suíça têm menores tarifas e conseguem ser mais competitivas (Ponciano et al., 2008 e Takano et al., 2021).

Embora apresente maior valor agregado que os outros tipos de café, a variação média das exportações do torrado e moído no período analisado foi de apenas $0,6 \%$. O baixo investimento no produto para comercialização no mercado externo pode ser uma das causas deste comportamento ao longo do tempo. Torrefadoras do setor em geral, são de pequeno porte e não costumam investir em diferenciação (Chain et al., 2016). Além disto, trabalham com estoques reduzidos de café verde adquiridos a preço do dia e geralmente altos, o que dificulta a produção de blends diferenciados e consequentemente, não atingem a competitividade no mercado externo (Abrantes et al., 2006).

Figura 3. Evolução das receitas de exportações cafeeiras do Brasil (2001-2019)

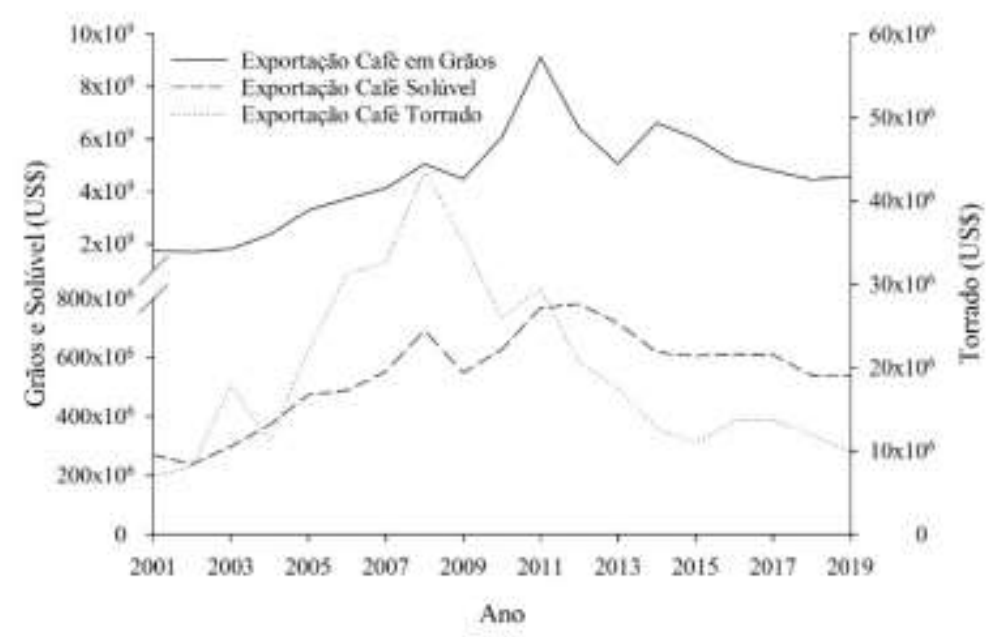

Fonte: Autores. 
A análise de correlação apresentada na Tabela 1, revelou que fatores como a produção ( $\mathrm{p}<0,05)$, produtividade, área e número de pés plantados $(\mathrm{p}<0,01)$, relacionaram-se negativamente com a taxa de câmbio no período analisado. De acordo com estudos realizados por Dixit e Pindyck (1994), este fato pode estar associado às incertezas dos produtores com relação aos preços negociados no mercado, que culminam em alterações temporárias ou definitivas no cultivo do café. Deve ser considerada ainda, certa dificuldade dos produtores para investir em insumos, pois os efeitos do câmbio causam reflexos nos seus custos.

Ponciano et al. (2008) consideram o uso de insumos como fator essencial para definir o nível produtivo dos cafeeiros. No que se refere às variações cambiais, Castro et al. (2005) afirmam que a valorização ou desvalorização da moeda nacional, provoca efeitos na produção agrícola com redução ou aumento no preço dos insumos que geralmente são importados. Sobre estas influências, Figueiredo et al. (1999) esclarecem que a desvalorização cambial, não aumenta o valor dos insumos em moeda estrangeira, mas sim, nos preços em moeda nacional.

O valor comercializado pela saca do café em grão, do torrado e moído ( $\mathrm{p}<0,01)$ e do café solúvel ( $\mathrm{p}<0,05)$, relacionou-se positivamente com o número de pés plantados no país, indicando que apesar dos frequentes aumentos na produção, o preço exerce impacto direto sobre a decisão dos produtores em aumentar ou reduzir suas lavouras. Este resultado corrobora com estudos realizados por Morozini et al. (2012), que identificaram maior predisposição dos produtores para o início de novas lavouras quando o preço do café apresenta variações positivas elevadas.

Tabela 1. Correlação de variáveis cafeeiras, cambiais e de exportação.

\begin{tabular}{lcccc}
\hline Variáveis & $\begin{array}{c}\text { Produção } \\
(\mathbf{s c ~ 6 0 ~ k g )}\end{array}$ & $\begin{array}{c}\text { Produtividade } \\
(\mathbf{s c / h a )}\end{array}$ & $\begin{array}{c}\text { Área } \\
\text { (hectares) }\end{array}$ & $\begin{array}{c}\text { Pés em } \\
\text { produção }\end{array}$ \\
\hline Produtividade (sc/ha) & $0.96^{*}$ & - & - & - \\
Área (ha) & $-0.49^{* *}$ & $-0.72^{*}$ & - & - \\
Pés em produção & $0.71^{*}$ & $0.76^{*}$ & $-0.65^{*}$ & - \\
Vr. saca grão (U\$) & - & - & - & $0.68^{*}$ \\
Vr. saca solúvel (U\$) & - & - & - & $0.72^{* *}$ \\
Vr. saca torrado (U\$) & - & - & - & $0.76^{*}$ \\
Exportaçães totais (U\$) & $0.48^{* *}$ & $0.50^{* *}$ & - & $0.48^{*}$ \\
Taxa de câmbio (R\$) & $-0.50^{* *}$ & $-0.58^{*}$ & $-0.64^{*}$ & $-0.84^{*}$ \\
\hline
\end{tabular}

Legenda: *Significância estatística a 0,01; **significância estatística a 0,05. Fonte: Dados do estudo.

O valor das exportações dos três tipos de café, apresentou elevada correlação negativa com a taxa de câmbio ( $\mathrm{p}<0,01)$.

Este comportamento indica que as receitas cambiais da cafeicultura brasileira, sofrem influência inversa às variações na taxa de câmbio, ou seja, se o dólar sofre desvalorização cambial, o valor pago pela saca de café diminui, ou se ocorre valorização cambial, o preço do café fica propenso a aumentar. Estas influências compensadas pela alta ou queda nos preços da saca de café comercializada no mercado externo, justificam-se devido às oscilações na oferta e demanda globais que tendem a estimular um preço de equilíbrio internacional (Krugman \& Obstfeld,2005).

Estudos comparativos entre Brasil, Colômbia e Peru realizados por Arevalo et al. (2016), identificaram que as receitas da exportação brasileira de café, sofrem os impactos das variações cambiais. Porém, Vasconcelos e Garcia (2014) ressaltam que não somente a taxa de câmbio, mas a interação entre oferta e demanda geralmente são responsáveis pela formação de preços de equilíbrio no mercado externo.

Ainda que os cafés solúvel, torrado e moído apresentem valor agregado e preços de comercialização superiores ao café em grão, este estudo identificou alta correlação no valor de exportação destes produtos (Tabela 2). 
Tabela 2. Correlação de variáveis de receitas cambiais das exportações cafeeiras e taxa de câmbio (US\$).

\begin{tabular}{lcccc}
\hline \multicolumn{1}{c}{ Variáveis } & $\begin{array}{c}\text { Export. grão } \\
\text { (US\$) }\end{array}$ & $\begin{array}{c}\text { Export. solúvel } \\
(\mathbf{U S \$})\end{array}$ & $\begin{array}{c}\text { Export. torrado } \\
(\mathbf{U S \$})\end{array}$ & $\begin{array}{c}\text { Export. totais } \\
\text { (US\$) }\end{array}$ \\
\hline Export. solúvel (US\$) & $0.92^{*}$ & - & - & - \\
Export. torrado (US\$) & $0.86^{*}$ & $0.93^{*}$ & - & - \\
Export. totais (US\$) & $0.91^{*}$ & $0.93^{*}$ & $0.91^{*}$ & - \\
Taxa de câmbio & $-0.86^{*}$ & $-0.93^{*}$ & $-0.92^{*}$ & $-0.92^{*}$ \\
\hline
\end{tabular}

Legenda: *Significância estatística a 0,01. Fonte: Dados do estudo.

Este comportamento sinaliza que o grão, como matéria-prima para os demais tipos de café, exerce interferência em toda cadeia industrial. Estudo semelhante realizado por Ponciano et al. (2008), que avaliou a estrutura agroindustrial cafeeira do Brasil, confirmou este resultado e identificou forte conexão da indústria cafeeira com o setor primário agrícola do país.

Além disto, as variações cambiais demonstraram influenciar toda a cadeia agroindustrial brasileira, configurando-se como fator de estímulo ao aumento ou queda da produção e das exportações.

\section{Conclusões}

Apesar da redução na área de plantio, a cafeicultura apresenta aumento no volume de café produzido e exportado ao longo do tempo. Além disto, as correlações estatísticas confirmaram existência de vínculos negativos entre os fatores produtivos cafeeiros e a taxa de câmbio, sugerindo maior predisposição dos produtores ao plantio, quando há incremento no preço.

As exportações cafeeiras do Brasil estão concentradas na fase inicial da cadeia, ou seja, no grão. O café solúvel apresenta pequena expansão, enquanto o café torrado e moído exibe comportamento de queda ao longo do tempo; não sendo avaliados neste estudo, aspectos competitivos da agroindústria cafeeira.

Sugere-se a realização de estudos futuros que considerem mercados cafeeiros e exportadores em âmbitos locais e regionais para identificação de possíveis gargalos existentes nas etapas produtivas e comerciais, que possam interferir na relação entre as exportações e os fatores produtivos.

\section{Referências}

Abrantes, L. A., Ferreira, M. A. M., Reis, R. P. \& Nazareth, M. S. (2006). Perfil estratégico e competitivo do segmento de torrefação e moagem de café em Minas Gerais. Anais do Congresso da Sociedade Brasileira de Economia, Administração e Sociologia Rural, Fortaleza, CE, Brasil, 44.

Arevalo, J. L. S., Arruda, D. O. de. \& Carvalho, J. P. de. (2016). Competitividade no comércio internacional do café: um estudo comparativo entre Brasil, Colômbia e Peru. Organizações Rurais \& Agroindustriais, 18(1), 62-78. http://revista.dae.ufla.br/index.php/ora/article/view/888.

Associação Brasileira da Indústria de Café Solúvel. (2020). Relatório do café solúvel do Brasil. https://www.abics.com.br/noticia.php?noticia=199\&relatorio_do_cafe_soluvel_do_brasil_jan eiro_de_2020.

Barreto, R. C. S. \& Zugaib, A. C. C. (2016). Dinâmica do mercado internacional de café e determinantes na formação de preços. Economia \& Região, 4(2), 727. http://dx.doi.org/10.5433/2317-627X.2016v4n2p7.

Begg, D., Fischer, S. \& Dornbusch, S. (2005). Economics (7a ed.). UK: McGraw-Hill Education publishing.

Bryan, M. F. \& Cecchettit, S. G. (1993). The Consumer Price Index as a Measure of Inflation. National Bureal of Economic Research. Working Paper 4505. https://doi.org/10.3386/w4505.

Caldarelli, C. E., Gilio, L. \& Zilberman, D. (2018). The coffee market in Brazil: challenges and policy guidelines. Revista de Economia, 39(69), 1-21. http://dx.doi.org/10.5380/re.v39i69.67891. 
Camargo, M. B. P. (2010). The impact of climatic variability and climate change on arabica coffee crop in Brazil. Bragantia, 69(1), 239-247.

Carrara, A. F. \& Correa, A. L. (2012). O regime de metas de inflação no Brasil: uma análise empírica do IPCA. Revista de Economia Contemporânea, 16(3), 441-462. https://doi.org/10.1590/S1415-98482012000300004.

Castro, E. R. de, Teixeira, E. C. \& Lima, J. E. de. (2005). Efeito da desvalorização cambial na oferta, no preço de insumos e na relação entre os fatores na cultura do café. Revista de Economia e Sociologia Rural, 43(3), 421-441. https://doi.org/10.1590/S0103-20032005000300002.

Chain, C. P., Carvalho, F. M. de. Sant`Ana, N. L. S. dos. Castro Júnior, L. G. C. \& Fontes, R. E. (2016). Aglomerações produtivas na indústria do café em minas gerais. Gestão \& Regionalidade, 32(94), 84-100. https://doi.org/10.13037/gr.vol32n94.2890.

Centro de Estudos Avançados em Economia Aplicada. (2013). Agromensal: café. https://www.cepea.esalq.usp.br/br/categoria/agromensal. aspx?mes $=12 \&$ ano $=2013$.

Companhia Nacional de Abastecimento. (2019). Acompanhamento da safra brasileira de café, Boletim dezembro 2019. Brasília, 5(3), 1-48. https://www.conab.gov.br/info-agro/safras/cafe.

Companhia Nacional de Abastecimento. (2020). Indicadores da Agropecuária. Brasília, 1, 01-88. https://www.conab.gov.br/info-agro/precos/revistaindicadores-da-agropecuaria. Acesso em 11 jul. 2020.

Conceição, J. C. P. R. da., Ellery Júnior, R. G. de. \& Conceição, P. H. Z. da. (2019). Cadeia agroindustrial do café no Brasil: agregação de valor e exportação. Boletim de Economia e Política Internacional, 24, 25-29.

Conselho de Exportadores de Café do Brasil. (2020). Relatório de mensal - dezembro 2020 . http://www.sapc.embrapa.br/arquivos/consorcio/informe_estatistico/CECAFE_Relatorio_Mensal_Dezembro_2020.pdf.

Copetti, L. S. \& Coronel D. A. (2019). Competitividade das exportações brasileiras e colombianas de café. Desenvolvimento Regional em debate, 9(1), 646667.

Dawid J. \& Hailu, G. (2018). Inorganic fertilizers requirement of coffee (Coffea arabica L.), a Review. Journal of Biology, Agriculture and Healthcare, 8(21), 24-34.

Dixit, A. \& Pindyck, R. (1994). Investment under uncertainty. Princeton NJ: Princeton University Press. 484 p.

Faleiros, R. N. \& Tosi, P. G. S. (2019). O café no Brasil: produção e mercado mundial na primeira metade do século XX. História Econômica \& História de Empresas, 22(2), 309-343.

Fávero, L. P. (2017). Manual de análise de dados. Elsevier.

Figueiredo, A. M., Ferreira, A. V. \& Teixeira, E. C. (1999). Impactos de uma desvalorização cambial sobre as relações de produção na cultura do café. Revista de Economia e Sociologia Rural, 37(4), 47-69.

Frederico, S. (2014). Globalização, competitividade e regionalização: a cafeicultura científica globalizada no território brasileiro. Geousp - Espaço e Tempo (Online), 18(1), 55-70.

Gurgel, A. C. (2014). Impactos de políticas comerciais e agrícolas sobre a agropecuária e a agroindústria brasileiras. Anais do Congresso Brasileiro de Economia e Sociologia Rural. Goiânia, GO, Brasil, 52.

Innocentini, M. (2015). Política brasileira do agronegócio do café: desafios e propostas. Revista de Política Agrícola, 24(1), 5-16.

Krugman, P. e Obstfeld, M. (2005). Economia Internacional: teoria e política (6a ed.). Pearson, 558 p.

Lacerda, A. C. de., Bocchi, J. I., Rego, J. M., Borges, M. A. e Marques, R. M. (2018). Economia brasileira (6a ed.). Saraiva, 328 p.

Marques, J. G. C. de., Paixão, S. K. da., Lyra, M. R. C. C., Carvalho, R. M. C. M. O. de. \& Silva, R. F. S. da. (2019). Gestão para a sustentabilidade no ambiente rural. Revista gestão e sustentabilidade ambiental, 8(4), 312-329. http://dx.doi.org/10.19177/rgsa.v8e42019312-329.

Matiello, J. B. (2005). Cultura de café no Brasil: novo manual de recomendações (2a ed.). Rio de Janeiro, RJ e Varginha, MG: Ministério da Agricultura, da Pecuária e do Abastecimento, 434 p.

Ministério da Agricultura, Pecuária e Abastecimento. (2019). Sumário executivo do café. Brasília, 12p. http://www.sapc.embrapa.br/arquivos/consorcio/informe_estatistico/Sumario_Cafe_Dezembro_2019.pdf.

Moreira, P., Moreira, G., Castro, N. \& Silva, R. P. (2019). Produtividade e economia de fatores de produção na cafeicultura brasileira. Revista de Política Agrícola, 2(1), 6-21.

Morozini, J. F., Martin, D. M. L. \& Cardoso, C. E. (2012). Teoria de opções reais para análise de risco e determinação dos preços de entrada e saída em uma lavoura de café no Brasil. Custos e @ gronegócio on line, 8(4), 2-24.

Organização Internacional do Café. (2020). Relatório mensal do mercado cafeeiro - dezembro 2020. http://www.ico.org/Market-Report-20-21-e.asp.

Pereira, A. S., Shitsuka, D. M., Parreira, F. J. \& Shitsuka, R. (2018). Metodologia da pesquisa científica. Universidade Federal de Santa Maria, 119p. https://repositorio.ufsm.br/bitstream/handle/1/15824/Lic_Computacao_Metodologia-Pesquisa-Cientifica.pdf?sequence=1. 
Research, Society and Development, v. 10, n. 3, e39210313503, 2021

(CC BY 4.0) | ISSN 2525-3409 | DOI: http://dx.doi.org/10.33448/rsd-v10i3.13503

Ponciano, N. J., Ney, M. G., Mata, H. T. C. da. \& Rocha, J. P. (2008, Julho). Dinâmica da cadeia agroindustrial do café (Coffea Arábica L.) brasileiro após a desregulamentação. Congresso da Sociedade Brasileira de Economia, Administração e Sociologia Rural, Rio Branco, Acre, Brasil, 21. http://dx.doi.org/10.22004/ag.econ.113969.

Ponciano, N. J., Souza, P. M. de. \& Ney, M. G. (2009). Ajustamentos na cadeia agroindustrial do café brasileiro. Revista IDeAS, 3(2), $256-287$.

Reuters. (2014). Safra de café 2012/13 cai após chuvas. Obtido em http://br.reuters.com/article/businessNews/idBRSPE88502Z20120906>.

Sereia, V. J. C. da., Gabardo, M. R. \& Cintra, M. V. (2008). Competitividade internacional do complexo cafeeiro brasileiro e paranaense. Semina: Ciências Agrárias, 29 (3), 557-578. http://dx.doi.org/10.5433/1679-0359.2008v29n3p557.

Sereia, V. J. C. da., Camara, M. R. G. \& Anhesini, J. A. R. (2012). Competitividade do complexo cafeeiro: uma análise a partir do market share e das vantagens comparativas simétricas. Revista de Economia, 38(1), 07-34.

Sório, A. (2015). Reposicionamento estratégico das indústrias processadoras de café do Brasil: propostas para sistematização de políticas públicas e estratégias de negócio. Passo Fundo: Méritos, 222 p.

Takano, A. L. R., Cabrera, L. C. \& Caldarelli, C. E. (2021). Cadeia produtiva e mercado cafeeiro no Brasil:desafios e potencialidades. Economia e Ensaios, $36(1), 128-145$.

Vasconcelos, M. A. S. \& Garcia, M. E. (2014). Fundamentos de economia (5a ed.). São Paulo: Saraiva, 368 p.

Verdin Filho, A. C., Volpi, P.S., Ferrão, M. A. G., Ferrão, R. G., Mauri, A. L., Fonseca, F. A. da, Tristão, F. A. \& Andrade Júnior, S. de. (2016). New management technology for arabica coffee: the cyclic pruning program for arabica coffee. Coffee Science, 11(4) 475 - 483.

Victorino, E. C., Carvalho, L. G. de. \& Ferreira, D. F. (2016). Modelagem agrometeorológica para a previsão de produtividade de cafeeiros na região Sul do Estado de Minas Gerais. Coffee Science, 11(2), 211 - 220. 